\title{
Carbon-based Solid Acid Catalyzed One-pot Mannich Reaction: A Facile Synthesis of $\beta$-Amino Carbonyl Compounds
}

\author{
Abolghasem Davoodnia, ${ }^{*}$ Afsaneh Tavakoli-Nishaburi, and Niloofar Tavakoli-Hoseini \\ Department of Chemistry, Faculty of Sciences, Mashhad Branch, Islamic Azad University, Mashhad, Iran \\ *E-mail: adavoodnia@mshdiau.ac.ir \\ Received November 9, 2010, Accepted December 14, 2010
}

\begin{abstract}
A simple and efficient method for the synthesis of $\beta$-amino carbonyl compounds by one-pot three-component Mannich reaction of acetophenone, aromatic aldehydes and aromatic amines using a carbon-based solid acid (CBSA), as an effective and reusable catalyst, is described. The present methodology offers several advantages such as simple procedure with an easy work-up, shorter reaction times, and high yields.
\end{abstract}

Key Words: Carbon-based solid acid, Mannich reaction, $\beta$-Amino carbonyl compounds

\section{Introduction}

Multicomponent reactions (MCRs) have recently received the attention of organic chemists because of the many advantages of these reactions offered over conventional multi-step synthesis as well as their potential applications in medicinal chemistry for the generation of diverse scaffolds and combinatorial libraries for drug development. ${ }^{1-3}$ In this type of reactions three or more components are reacted to form ideally one product, which contains the essential parts of all the initial reactants. MCRs contribute to the requirements of an environmentally friendly process by reducing the number of synthetic steps, energy consumption and waste production. Therefore, the discovery for new MCRs and improving the already known MCRs are of considerable interest. One such reaction is the synthesis of $\beta$-amino carbonyl compounds by the Mannich reaction.

The Mannich reaction is one of the most basic and useful synthetic methods for the preparation of $\beta$-amino carbonyl compounds and has been one of the most important reactions in organic chemistry for its use in various pharmaceuticals, natural products, and versatile synthetic intermediates. ${ }^{4}$ The reported Mannich reactions have been catalyzed by various Lewis or Brønsted acid catalysts such as acetic acid, ${ }^{5}$ ceric ammonium nitrate, ${ }^{6} \mathrm{HCl}^{7} \mathrm{HBF}_{4},{ }^{8,9}$ rare earth perfluorooctanoate, ${ }^{10}$ silicasupported aluminum chloride, ${ }^{11} \mathrm{BiCl}_{3},{ }^{12}$ sulfamic acid, ${ }^{13}$ and $\mathrm{Bi}(\mathrm{OTf})_{3} .{ }^{14}$ However, they often suffer from the drawbacks of long reaction times and harsh reaction conditions, toxicity, and difficulty in product separation, which limit its use in the synthesis of complex molecules. Furthermore, some of them are corrosive and volatile, and often cause the environment problems. Therefore, the development of simple, efficient, high-

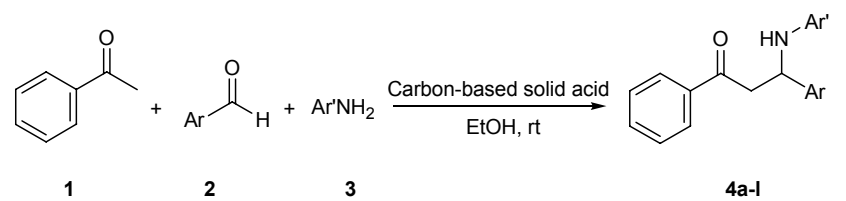

Scheme 1. Mannich reaction catalyzed by CBSA yielding, and environmentally friendly methods using new catalysts for the Mannich reaction is still necessary.

Using solid acid catalysts have some advantages such as ease of products separation, recycling of the catalyst and environmental acceptability as compared to liquid acid catalyst. ${ }^{15} \mathrm{Car}-$ bon-based solid acid (CBSA) catalyst has many advantages. It is insoluble in common organic solvents, causes low corrosion, and shows environmental acceptability. Also the products could be easily separated from the reaction mixture and the catalyst is recoverable without decreasing its activity. Therefore, it can be successfully used instead of sulfuric acid as catalyst. ${ }^{16,17}$ To the best of our knowledge, there are no examples on the use of CBSAs as catalysts for the synthesis of $\beta$-amino carbonyl compounds by the Mannich reaction.

In continuation of our previous works on the applications of reusable catalysts in the synthesis of organic compounds, ${ }^{18-27}$ we report herein a new and efficient synthesis of $\beta$-amino carbonyl compounds by condensation of acetophenone, aromatic aldehydes and aromatic amines using CBSA as a catalyst (Scheme 1).

\section{Experimental}

All chemicals were available commercially and used without additional purification. The catalyst was synthesized according to the known literature. Melting points were recorded on an electrothermal type 9100 melting point apparatus. The IR spectra were obtained using a 4300 Shimadzu spectrophotometer as $\mathrm{KBr}$ disks. The ${ }^{1} \mathrm{H}$ NMR $(500 \mathrm{MHz})$ spectra were recorded with a Bruker DRX500 spectrometer.

Preparation of CBSA. The CBSA was prepared according to the reported procedure by Hara and co-workers. ${ }^{16}$ Naphthalene $(20 \mathrm{~g})$ was heated in concentrated sulfuric acid $(>96 \%, 200 \mathrm{~mL})$ at $250{ }^{\circ} \mathrm{C}$ under a flow of $\mathrm{N}_{2}$. After heating for $15 \mathrm{~h}$, excess sulfuric acid was removed from the dark brown tar by vacuum distillation at $250{ }^{\circ} \mathrm{C}$ for $5 \mathrm{~h}$, which resulted in a black solid. The solid was then ground to a powder and was washed repeatedly in boiling water until impurities such as sulfate ions were no longer detected in the wash water. The density of the $\mathrm{SO}_{3} \mathrm{H}$ 
group was measured using $\mathrm{NaOH}(0.01 \mathrm{~mol} / \mathrm{L})$ as titrant by acidbase potentiometric titration. The amount of $\mathrm{SO}_{3} \mathrm{H}$ attached to the polycyclic aromatic carbon was $2.84 \mathrm{mmol} / \mathrm{g}$.

General Procedure for the Synthesis of $\beta$-amino Carbonyl Compounds by CBSA Catalyzed Mannich Reaction. To a mixture of acetophenone $(2 \mathrm{mmol})$, aromatic aldehyde $(2 \mathrm{mmol})$ and aromatic amine $(2 \mathrm{mmol})$ in ethanol $(5 \mathrm{~mL}), \mathrm{CBSA}(0.10 \mathrm{~g})$ was added. The mixture was stirred at room temperature and the reaction was monitored by TLC. Upon completion, the mixture was heated up to boiling. The catalyst was dissolved in hot ethanol and filtered off. The product was collected from the filtrate after cooling to room temperature and recrystallized from ethanol to give compounds $\mathbf{4 a - 1}$ in high yields.

\section{Results and Discussion}

The one-pot synthesis of $\beta$-amino carbonyl compounds was achieved by the three-component condensation of acetophenone, aromatic aldehydes and aromatic amines in the presence of CBSA as a heterogeneous catalyst (Scheme 1). CBSA was prepared according to the literature procedure. ${ }^{16}$ Initially, the synthesis of compound $\mathbf{4 b}$ was selected as a model reaction to optimize the reaction conditions. The reaction was carried out by stirring a mixture of acetophenone $(2 \mathrm{mmol})$, benzaldehyde $(2 \mathrm{mmol})$ and 4-chloroaniline $(2 \mathrm{mmol})$ in ethanol in the presence of various amount of CBSA as a catalyst.

The efficiency of the reaction is affected mainly by the amount of CBSA (Table 1). No products were produced in the absence of the catalyst (entry 1). To give the product, the catalyst is necessary for the reaction. Increasing the amount of the cat-

Table 1. Effect of the amounts of CBSA on the model reaction ${ }^{a}$

\begin{tabular}{cccc}
\hline Entry & Catalyst $(\mathrm{g})$ & Time $(\mathrm{h})$ & ${\text { Yield }(\%)^{b}}^{b}$ \\
\hline 1 & None & 8 & None \\
2 & 0.04 & 8 & 75 \\
3 & 0.06 & 7 & 77 \\
4 & 0.08 & 5.5 & 81 \\
5 & 0.10 & 4.5 & 93 \\
6 & 0.12 & 4.5 & 93 \\
7 & 0.15 & 5.5 & 94
\end{tabular}

acetophenone (2 $\mathrm{mmol})$, benzaldehyde $(2 \mathrm{mmol})$, 4-chloroaniline $(2 \mathrm{mmol})$ in ethanol at $\mathrm{rt} .{ }^{b}$ Isolated yields.

Table 2. Synthesis of compound $4 \mathbf{b}$ in the presence of CBSA $(0.10 \mathrm{~g})$ in different solvents at $\mathrm{rt}^{a}$

\begin{tabular}{cccc}
\hline Entry & Solvent & Time $(\mathrm{h})$ & ${\text { Yield }(\%)^{b}}^{b}$ \\
\hline 1 & EtOH & 4.5 & 93 \\
2 & $\mathrm{THF}$ & 10 & 78 \\
3 & $\mathrm{H}_{2} \mathrm{O}$ & 10 & Trace \\
4 & $\mathrm{CH}_{3} \mathrm{CN}$ & 10 & Trace \\
5 & $\mathrm{CHCl}_{3}$ & 10 & Trace \\
6 & Solvent-free & 10 & Trace \\
\hline
\end{tabular}

$\bar{a}$ acetophenone $(2 \mathrm{mmol})$, benzaldehyde $(2 \mathrm{mmol})$, 4-chloroaniline $(2 \mathrm{mmol})$ at $\mathrm{rt} .{ }^{b}$ Isolated yields.

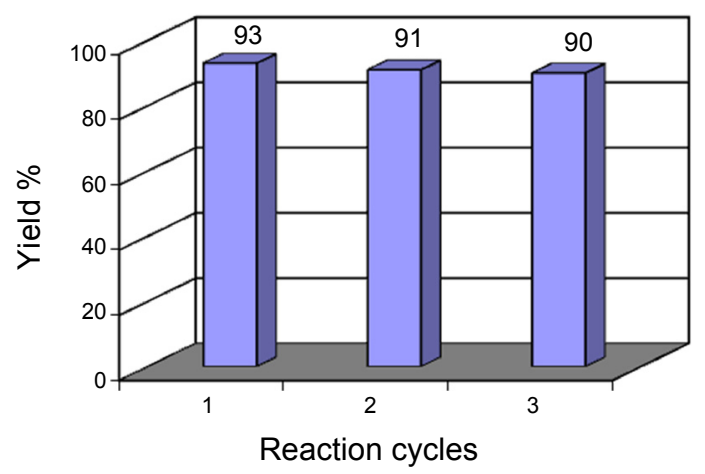

Figure 1. Reusability of CBSA for model reaction.

alyst increased the yield of the product $\mathbf{4 b}$. The optimal amount of CBSA was $0.10 \mathrm{~g}$ (entry 5); increasing the amount of the catalyst beyond this value did not increase the yield noticeably (entries 6-7).

Furthermore, the reaction was carried out in different solvents and under solvent-free conditions. As shown in Table 2, EtOH was the best choice among the solvents screened. The compound $\mathbf{4 b}$ was obtained in good yield in THF but in trace amount in $\mathrm{H}_{2} \mathrm{O}, \mathrm{CH}_{3} \mathrm{CN}, \mathrm{CHCl}_{3}$ and also in solvent-free condition after $10 \mathrm{~h}$ at room temperature.

In order to evaluate the generality of this model reaction, other aldehydes and amines were tested for the Mannich reactions with acetophenone in ethanol at room temperature. The type of aldehydes and amines had no significant effect on the reaction. The results are summarised in Table 3.

Reusability of the catalyst was also investigated. For this purpose, the same model reaction was again studied under optimized conditions. After the completion of the reaction, the reaction mixture was heated up to boiling. The catalyst was separated by simple filtration, dried at $60^{\circ} \mathrm{C}$ under vacuum for $1 \mathrm{~h}$, and reused for a similar reaction. As shown in Fig. 1, the catalyst could be reused at least three times without significant loss of activity.

\section{Conclusion}

In conclusion, we have reported a simple and new catalytic method for the synthesis of $\beta$-amino carbonyl compounds by one-pot three-component Mannich reaction of acetophenone, aromatic aldehydes, and aromatic amines using CBSA as an efficient, reusable, and green heterogeneous catalyst. The catalyst can be recycled after a simple work-up, and used at least three times without substantial reduction in its catalytic activity. High yields, relatively short reaction times, and easy workup are just a few of the advantages of this procedure.

Acknowledgments. The authors are thankful to Islamic Azad University, Mashhad Branch for financial support.

\section{References}

1. Thomson, L. A.; Ellman, J. A. Chem. Rev. 1996, 96, 555.

2. Dömling, A.; Ugi, I. Angew. Chem. Int. Ed. 2000, 39, 3169. 
Table 3. Carbon-based solid acid catalyzed Mannich reaction ${ }^{a}$

\begin{tabular}{|c|c|c|c|c|c|c|c|c|}
\hline \multirow{2}{*}{ Entry } & \multirow{2}{*}{$\mathrm{Ar}$} & \multirow{2}{*}{$\mathrm{Ar}^{\prime}$} & \multirow{2}{*}{ Products $^{b}$} & \multirow{2}{*}{ Time (h) } & \multirow{2}{*}{ Yield $(\%)^{c}$} & \multicolumn{2}{|c|}{$\mathrm{mp}\left({ }^{\circ} \mathrm{C}\right)$} & \multirow{2}{*}{ Ref. } \\
\hline & & & & & & Found & Reported & \\
\hline 1 & $\mathrm{C}_{6} \mathrm{H}_{5}$ & $\mathrm{C}_{6} \mathrm{H}_{5}$ & & $3: 45$ & 90 & $168-170$ & $170-171$ & 10 \\
\hline 2 & $\mathrm{C}_{6} \mathrm{H}_{5}$ & 4- $\mathrm{ClC}_{6} \mathrm{H}_{4}$ & & 4.5 & 93 & $174-176$ & $170-171$ & 10 \\
\hline 3 & $\mathrm{C}_{6} \mathrm{H}_{5}$ & $3-\mathrm{O}_{2} \mathrm{NC}_{6} \mathrm{H}_{4}$ & & 4 & 91 & $146-148$ & 138-139 & 10 \\
\hline 4 & $4-\mathrm{BrC}_{6} \mathrm{H}_{4}$ & $\mathrm{C}_{6} \mathrm{H}_{5}$ & & 7 & 88 & $137-139$ & $123-127$ & 6 \\
\hline 5 & $4-\mathrm{ClC}_{6} \mathrm{H}_{4}$ & $\mathrm{C}_{6} \mathrm{H}_{5}$ & & 7 & 87 & $117-118$ & $114-115$ & 11 \\
\hline 6 & $4-\mathrm{ClC}_{6} \mathrm{H}_{4}$ & $4-\mathrm{ClC}_{6} \mathrm{H}_{4}$ & & $4: 20$ & 90 & $124-126$ & 118-119 & 11 \\
\hline 7 & $4-\mathrm{ClC}_{6} \mathrm{H}_{4}$ & $3-\mathrm{O}_{2} \mathrm{NC}_{6} \mathrm{H}_{4}$ & & $5: 15$ & 92 & $142-144$ & $132-133$ & 11 \\
\hline 8 & $4-\mathrm{MeOC}_{6} \mathrm{H}_{4}$ & $\mathrm{C}_{6} \mathrm{H}_{5}$ & & 6.5 & 84 & $153-156$ & $142-143$ & 11 \\
\hline 9 & $4-\mathrm{MeOC}_{6} \mathrm{H}_{4}$ & $4-\mathrm{ClC}_{6} \mathrm{H}_{4}$ & & 4.5 & 89 & $162-164$ & $158-160$ & 12 \\
\hline 10 & $4-\mathrm{MeC}_{6} \mathrm{H}_{4}$ & $\mathrm{C}_{6} \mathrm{H}_{5}$ & & 6 & 87 & $138-140$ & $134-135$ & 11 \\
\hline 11 & $3-\mathrm{O}_{2} \mathrm{NC}_{6} \mathrm{H}_{4}$ & $\mathrm{C}_{6} \mathrm{H}_{5}$ & & 7 & 87 & $140-142$ & $131-132$ & 11 \\
\hline 12 & $4-\mathrm{O}_{2} \mathrm{NC}_{6} \mathrm{H}_{4}$ & $\mathrm{C}_{6} \mathrm{H}_{5}$ & & 6.5 & 89 & $115-117$ & $105-106$ & 12 \\
\hline
\end{tabular}

${ }^{a}$ Acetophenone $(2 \mathrm{mmol})$, aromatic aldehyde $(2 \mathrm{mmol})$, aromatic amine $(2 \mathrm{mmol})$ in ethanol at $\mathrm{rt} .{ }^{b}$ All the products were characterized by IR spectral data and comparision of their melting points with those of authentic samples. Also, the structures of some products were confirmed by ${ }^{1} \mathrm{H}$ NMR spectral data. ${ }^{c}$ Isolated yields. 
3. Dandia, A.; Singh, R.; Sarawgi, P.; Khaturia, S. Chin. J. Chem. 2006, 24, 950 .

4. Arend, M.; Westermann, B.; Risch, N. Angew. Chem. Int. Ed. 1998, 37, 1044.

5. Mogilaiah, k.; Kankaiah, G. Indian J. Heterocycl. Chem. 2002, 11, 283.

6. Kidwai, M.; Bhatnagar, D.; Mishra, N. K.; Bansal, V. Catal. Commun. 2008, 9, 2547.

7. Akiyama, T.; Matsuda, K.; Fuchibe, K. Synlett 2005, 2, 322.

8. Akiyama, T.; Takaya, J.; Kagoshima, H. Synlett 1999, 7, 1045.

9. Akiyama, T.; Itoh, J.; Fuchibe, K. Synlett 2002, 8, 1269.

10. Wang, L.; Han, J.; Sheng, J.; Tian, H.; Fan, Z. Catal. Commun. 2005, 6, 201

11. Li, Z.; Ma, X.; Liu, J.; Feng, X.; Tian, G.; Zhu, A. J. Mol. Catal. A: Chem. 2007, 272, 132

12. Li, H.; Zeng, H.; Shao, H. Tetrahedron Lett. 2009, 50, 6858.

13. Zeng, H.; Li, H.; Shao, H. Ultrason. Sonochem. 2009, 16, 758.

14. Ollevier, T.; Nadeau, E. Synlett 2006, 2, 219.

15. Okuhara, T. Chem. Rev. 2002, 102, 3641.

16. Hara, M.; Yoshida, T.; Takagaki, A.; Takata, T.; Kondo, J. N.; Hayashi, S.; Domen, K. Angew. Chem., Int. Ed. 2004, 43, 2955.
17. Zhou, L.; Liu, K.; Hua, W. M.; Yue, Y. H.; Gao, Z. Chin. J. Chem. 2009, 30, 196

18. Davoodnia, A.; Bakavoli, M.; Barakouhi, Gh.; Tavakoli-Hoseini, N. Chin. Chem. Lett. 2007, 18, 1483.

19. Davoodnia, A.; Roshani, M.; Malaeke, S. H.; Bakavoli, M. Chin. Chem. Lett. 2008, 19, 525.

20. Davoodnia, A.; Heravi, M. M.; Rezaei-Daghigh, L.; TavakoliHoseini, N. Monatsh. Chem. 2009, 140, 1499.

21. Davoodnia, A.; Bakavoli, M.; Moloudi, R.; Khashi, M.; TavakoliHoseini, N. Chin. Chem. Lett. 2010, 21, 1.

22. Davoodnia, A.; Bakavoli, M.; Moloudi, R.; Khashi, M.; TavakoliHoseini, N. Monatsh. Chem. 2010, 141, 867.

23. Davoodnia, A.; Heravi, M. M.; Safavi-Rad, Z.; Tavakoli-Hoseini, N. Synth. Commun. 2010, 40, 2588.

24. Davoodnia, A.; Heravi, M. M.; Rezaei-Daghigh, L.; TavakoliHoseini, N. Chin. J. Chem. 2010, 28, 429.

25. Davoodnia, A.; Allameh, S.; Fakhari, A. R.; Tavakoli-Hoseini, N. Chin. Chem. Lett. 2010, 21, 550.

26. Tavakoli-Hoseini, N.; Davoodnia, A. Asian J. Chem. 2010, 22, 7197.

27. Davoodnia, A. Asian J. Chem. 2010, 22, 1595. 